\title{
NARRATIVAS DE FORMAÇÃO, (AUTO) BIOGRAFIA E INCLUSÃO: EXPERIÊNCIAS DE PROFESSORES E ALUNOS NO ENSINO MÉDIO
}

\author{
A. L. A. L. LEANDRO ${ }^{1}$; M. A. C. COSTA ${ }^{2}$ e S. S. AQUINO ${ }^{3}$ \\ 1,2,3 Universidade do Estado do Rio Grande do Norte \\ E-mail: oliveiraaguiar@msn.com ${ }^{1}$, mifraangelica@hotmail.com ${ }^{2}$, shirleyannequino@hotmail.com ${ }^{3}$
}

Artigo submetido em novembro/2011 e aceito em março/2012

\section{RESUMO}

Trata de narrativas de formação na voz de professores e alunos centradas na carreira e nas trajetórias escolares com experiências de inclusão. Objetiva compreender ações que originaram rupturas e mudanças na perspectiva da construção da autonomia e independência de alunos com deficiência durante suas vivências escolares, buscando mostrar como as (auto) biografias estão carregadas de sentido e da dimensão formadora. A subjetividade ocupa um lugar central como via do lugar do sujeito, do narrar de si e do outro, do cuidar de si e do outro. Trabalha a abordagem (auto) biográfica no sentido de explorar aspectos da memória e do "eu" do professor e do aluno, fazendo sentido e construindo o lugar do outro em sua trajetória de formação. Mantoan (2006), Passegi (2011), Souza (2003) e Bueno (1996) serão os aportes teóricos das narrativas (auto) biográficas e de inclusão. Conhecer, significar e ressignificar práticas pedagógicas, na relação com alunos com deficiência, a partir das narrativas de professores, permitiram verificar o que professores do Ensino Médio estão construindo no cotidiano da sala de aula no que diz respeito ao atendimento à Política de Educação Especial na Perspectiva da Educação Inclusiva e, através das narrativas de alunos surdos, apresentar como se deu seu processo de inserção e permanência numa escola de Ensino Médio numa perspectiva inclusiva. Ao mesmo tempo trouxe sutilezas pedagógicas que apontaram desafios e possibilidades para o exercício da profissão docente e para vivências escolares. Essas narrativas representaram um exercício provocativo às nossas práticas de sala de aula e experenciadores de rupturas do conservadorismo e, principalmente, o exercício do questionar a naturalização do espaço da escola.

PALAVRAS-CHAVE: Ensino Médio, (auto) Biografia, formação, inclusão.

\section{NARRATIVES OF TRAINING, (AUTO) BIOGRAPHY AND INCLUSION: EXPERIENCES OF TEACHERS AND STUDENTS IN HIGH SCHOOL}

\begin{abstract}
These narratives of education as expressed by teachers and students focused on career and experiences in school history with inclusion. Aims to understand actions that led to disruptions and changes in perspective of the construction of autonomy and independence of students with disabilities during their school experiences, seeking to show how the (auto) biographies are full of meaning and scale forming. Subjectivity occupies a central place to track the subject, the narrative of self and other, of caring for self and others. The approach works (auto) biography in order to explore aspects of memory and "I" of the teacher and student, making sense and constructing the other's place in your career training. Mantoan (2006), Passegi (2011), Souza (2003) and Bueno (1996) are the theoretical narratives of (auto) biographical and inclusion. Knowing,
\end{abstract}

signifying and reframe pedagogical practices in relation to students with disabilities, through the narratives of teachers, helped confirm that secondary school teachers are building in the routine of the classroom with regard to compliance with the Special Education Policy perspective of Inclusive Education, and through the narratives of deaf students, presenting as it did the process of integration and retention in secondary school an inclusive perspective. At the same time brought subtleties pointed pedagogical challenges and opportunities to pursue the teaching profession and school experiences. These narratives were a provocative exercise our practices and classroom disruptions experience conservatism, and especially the exercise of the question the naturalization of the school space.

KEY-WORDS: School, (auto) biography, training, inclusion. 


\section{NARRATIVAS DE FORMAÇÃO, (AUTO) BIOGRAFIA E INCLUSÃO: EXPERIÊNCIAS DE PROFESSORES E ALUNOS NO ENSINO MÉDIO}

\section{INTRODUÇÃO}

Ao discutir políticas objetivando superar a situação de exclusão de alunos com necessidades educacionais especiais nos reportamos a uma legislação que, podemos afirmar, é decorrente de discussões internacionais e nacionais avançadas do ponto de vista das letras. Por outro lado dúvidas, receios, incertezas, buscas do como fazer, bem como de debates sobre o lado reverso da medalha são aquecidos entre os docentes no interior das escolas.

O debate nos leva para a Política de Inclusão dentro da Legislação Educacional Brasileira para o Ensino Médio. Este nos joga para bem dentro do epicentro das questões e do que, em decorrência do despreparo das escolas, está sendo gestado. Por sua vez, oportuniza um percurso presente e pontual do ponto de vista do que prescreve a lei em sua relação com o que está sendo construído em sala de aula, pela via da prática dos professores, e pela via do cotidiano dos alunos na vivência do que aponta a política de inclusão.

Os ganhos indicados pela lei se tornam um desafio para professores, para os alunos, para a família e para a sociedade. A formação inicial dos professores, a persistência por uma formação continuada, a presença dos pais na escola, a participação de toda a sociedade são pontos fortes para reflexão.

Não há como andar em linha contrária. Estamos todos implicados e convocados às mudanças. Comprometidos com a diversidade e a inclusão, com o exercício da lei, com a remoção de barreiras físicas, com um pensar sobre a formação inicial na perspectiva formativa, devemos instigar um olhar diferente para o hoje, construindo um espaço aberto para ações que superem as assertivas que pairam no senso comum de que "a lei diz uma coisa, na escola temos outra"; eles não sabem o que escrevem porque estão em seus gabinetes"; "não posso fazer nada com o que temos na escola".

São crenças que, uma vez não diluídas, continuarão circulando no trânsito engarrafado pelas convicções em dois pólos diferentes: de um lado, o "estranho" que elabora a lei e, do outro lado aqueles que estão no palco do exercício de sua profissão docente e que "sentem na pele os efeitos daquela".

Com vários anos no exercício da docência, professores anunciam que a maior barreira é o seu despreparo para atender alunos com deficiência considerando que teriam que dar conta não só de uma literatura fundamentadora da visão de mundo e de educação, como das metodologias para as diversas situações de deficiência. Ao mesmo tempo, há que se dar conta de outra tensão: pais duvidosos de que a escola vá enfrentar suas questões de inclusão com o mínimo de preparo. Temem, com esse entendimento, que seus filhos passem por situações de agressão, de estigma, de constrangimento. Essa lógica é recorrente na fala dos pais, principalmente, da mãe que prefere não expor seu filho a uma escola que "na maioria das vezes não tem, e vejo isso até na hora da merenda, um professor orientador com postura pedagógica para o acompanhamento das crianças, que deveriam ser, brincadeiras lúdicas".

Temos consciência de que a Declaração Universal dos Direitos Humanos, nos seus anos 70, já instigava o debate sobre o direito da pessoa com deficiência. No entanto, outros espaços e discussões geraram avanços como: a celebração do Ano Internacional das Pessoas Deficientes, em 1981; a Década das Nações Unidas para as Pessoas Com Deficiência, 1983/1992; a Conferência sobre Educação para Todos, com lugar em Jontien, na Tailândia e promovido pela 
UNESCO; a Conferência Mundial da UNESCO sobre Necessidades Educativas Especiais quanto ao acesso das pessoas com deficiência ao Ensino regular; a Declaração de Salamanca advogando a pertinência e a força do movimento da escola inclusiva. Por sua vez o Ministério de Educação e Cultura, com seus cadernos de Educação Especial, Inclusão, nos permite um firme aporte sobre o percurso da Lei no âmbito dessa discussão.

No Brasil avanços teóricos e práticos inspiram muitos, provocam outros, desanimam outros tantos. Olhos estão girando em torno dos pedidos sobre o cumprimento, pelos governantes, pelas Secretarias de Educação locais, do prescrito pelas leis da Educação Especial na Perspectiva da Educação Inclusiva. Temos clara certeza de que as leis ainda não são satisfatórias e suficientes. Sua regulação abre espaço para outras exigências nascidas na gênese das mesmas. Pensamos, por exemplo, na ausência de um intérprete na sala de aula cuja presença é obrigatória de acordo com a lei.

O DECRETO № 5.626, DE 22 DE DEZEMBRO DE 2005 orienta sobre a inclusão do tradutor e do intérprete de Libras-Língua Portuguesa para o acesso à comunicação, à informação e à educação de alunos surdos. Esse profissional é pertinente para "viabilizar o acesso dos alunos aos conhecimentos curriculares, em todas as atividades didáticas e pedagógicas". Esse é um dos exemplos do que diz a lei.

Preocupações sentimos nos estudos de MANTOAN (2006 p. 25) quando se refere que "anteriormente os pais e professores desses alunos não tinham conhecimento das leis que promovem indiscriminadamente o acesso de todos à educação comum. Hoje corajosamente o movimento escolar inclusivo se encarrega de conscientizar pais e professores destes direitos".

Essa preocupação vai alimentando tantas outras. Cria vínculos, redes de conversa. Estamos com uma formação limitada não resta dúvida. Vemos com a mesma consistência a presença de novos sujeitos das relações sociais, como protagonizando seus papéis nessa mesma direção de interesse.

Refletimos, para este artigo, sobre o que pensam professores e alunos sobre essa discussão, sobre como professores alimentam sua formação continuada, sobre como os alunos vivem na prática e pensam essa discussão.

A Resolução CNE/CEB (no 02 Art. 4ㅇ Inciso I de 2001), no seu artigo 2으, orienta para que no sistema regular de ensino todos os alunos sejam matriculados e que a escola deve se organizar para todos os alunos com necessidades educacionais especiais. Essa organização, no entanto, implica que a escola assegure as condições necessárias em torno de uma educação de qualidade para todos.

A Lei de Diretrizes e Bases, em seu Cap. 5, Da Educação Especial, avisa que os sistemas de ensino assegurarão aos educando com necessidades especiais "currículos, métodos, técnicas, organização específicos para atender às suas necessidades.

Frente ao até agora discutido tivemos a preocupação de ouvir os protagonistas desse processo na escola. O que estão, coletivamente, fazendo, pensando, buscando e organizando no espaço escolar na junção das idéias, na arrumação desses pedaços, na cimentação do quebrado?

Para este artigo, professores e alunos do Ensino Médio são atores e cenário escolhidos. Essa escolha nos encaminhou para a metodologia da aproximação aos sujeitos e na construção e reconstrução do saber fazer de cada um no seu lugar de ação. A metodologia da História Oral e (auto) Biográfica foi vivenciada desejando desde a palavra falada, passando pelo não dito, capturando as expressões não verbais, o silenciado. 


\section{A PERSPECTIVA (AUTO) BIOGRÁFICA E EXPERIÊNCIA FORMATIVA}

No âmbito das discussões contemporâneas em educação há um forte interesse e experiências múltiplas pela metodologia da pesquisa (auto) biográfica. Essa tendência se preocupa com o valor das fontes primárias colocando a sua central pertinência quando pensamos em reconstruir experiências e vivências de sujeitos, homens e mulheres, da sociabilidade simples.

Bueno (1996), em seu trabalho 0 método autobiográfico e os estudos com histórias de professores: a questão da subjetividade considera que a partir de 1980 houve um redirecionamento dos estudos sobre formação docente buscando aprofundar essa tendência de pesquisa em Educação em seu diálogo com as pesquisas (auto) Biográficas. Citando Antonio Nóvoa visualizamos as ênfases sobre a pessoa do professor, as carreiras e os percursos profissionais nas autobiografias docentes ou o desenvolvimento pessoal dos professores (NÓVOA, 1982).

A pessoa do professor vai para o centro do interesse dando uma virada nos estudos feitos anteriores ao período de 1980. Várias são as justificativas apontadas por Bueno (1998) para essa tendência afirmando sobre a potencialidade dos novos métodos para a pesquisa e para a prática dos professores. No entanto, um elemento central, diz a autora, é a questão da subjetividade. Argumenta que esse aspecto ficou esquecido e que a partir de 1980 passa a se constituir como elemento articulador, central, das novas formulações teóricas e das propostas realimentadoras da área. Em seu estudo na seção A Subjetividade Reinventada parte de questionamentos sobre a influência exercida pelos métodos experimentais no âmbito das ciências físicas e biológicas para investigar os fenômenos sociais. Afirma que o que foi fascínio inicial conduziu a uma verdadeira tirania em relação ao paradigma clássico. Esse, segundo Bueno, trata-se de um ponto que deu origem às insatisfações indicando um movimento de rupturas e mudanças não só na busca de novos métodos de investigação como um novo modo de conceber a própria ciência. Assim, as regularidades, as situações estáveis dão lugar às instabilidades, as evoluções, às crises. São mudanças paradigmáticas, segundo a autora, e as rupturas que se ocupam as ciências sociais no decorrer do século XX.

A subjetividade, nesse percurso de discussão e polêmica, vai ganhando o centro das discussões e se constituindo em objeto de estudo.

$\mathrm{Na}$ compreensão de Souza (2003), concordando com Ferraroti (1988) defende que a utilização do método biográfico corresponde à exigência de uma renovação metodológica como forma de rompimento com a metodologia clássica das ciências sociais, centrada na objetividade e na intencionalidade. Com a mesma intensidade de renovação, sobre a perspectiva dos sujeitos, as vias de compreensão sobre a vida cotidiana, tensões, contradições, medos, alegrias, ações. Discutindo em $\mathbf{A}$ arte de contar e trocar experiências: reflexões teórico-metodológicas sobre histórias de vida em formação Souza, aludindo a Ferraroti, compreende que as estruturas sociais se movimentam em sua tradução para comportamentos individuais e microssociais.

Ainda juntando-se a Ferraroti, Souza diz que suas reflexões pontuam aspectos sobe as metamorfoses, especificidades do método biográfico e as mediações sociais do trabalho com as biografias de grupos, na medida em que o homem no seu cotidiano universal pode ser tomado para análise como referência da totalidade da experiência humana, reproduzindo-se na sua singularidade.

Passegi, Souza e Vicentini (2003), em seu texto Dossiê (Auto) Biografia e Educação: pesquisa e práticas de formação entendem que a aprendizagem da convivência pacífica implica o respeito ao outro e a resolução de conflitos através do diálogo. Aponta a abertura para a 
alteridade como um percurso a ser trilhado passando pelo conhecimento de si. Coloca uma provocação, a nosso juízo, para todos nós, a saber, aquela de se descobrir caminhos para ajudar a melhorar nas instituições de ensino, e em seus diferentes níveis, o combate à violência física e simbólica tanto na escola como fora dela. Salienta a centralidade no sujeito como agente e paciente que pratica e sofre no seio de grupos sociais conduzindo cada vez mais a se investigarem e a estreita relação entre aprendizagem e reflexividade (auto) biográfica. Ainda alude à importância de estudar como os sujeitos dão forma a suas existências e sentido ao que antes não tinha. Conhecer, ler, ouvir a vida do outro é um modo de formação.

Tomamos como sujeitos da investigação discentes surdos que tiveram sua passagem pelo Ensino Médio na Educação de Jovens e Adultos. Observamos e entrevistamos dois estudantes surdos. As entrevistas foram realizadas através de rodas de conversa cuja discussão permeou a trajetória de aprendizagem e inclusão quando de sua passagem pelo Ensino Médio em uma escola pública da Rede de Ensino de Mossoró.

O interesse era o de investigar se em sua trajetória de vida foi possível conhecer, significar e ressignificar práticas pedagógicas e escolares, na relação com alunos com deficiência. Ainda o de verificar o que professores do Ensino Médio estão construindo no cotidiano da sala de aula no que diz respeito ao atendimento à Política de Educação Especial na Perspectiva da Educação Inclusiva. Ainda, através das narrativas de alunos surdos, apresentar como se deu seu processo de inserção e permanência numa escola de Ensino Médio numa perspectiva inclusiva.

Esse estudo centra-se em relatos na interação social entre pesquisador e informante em torno de situação de estudo e formação no Ensino Médio. O artigo se ocupa de dois alunos surdos e as transformações e/ou permanências de si, dos professores, da instituição frente a um eixo central: práticas e vivências de inclusão durante sua trajetória no Ensino Médio.

Os estudos (auto) biográficos tomam as narrativas como discursos constituídos de memória. Seu papel é central considerando a liberdade dos sujeitos em narrar, dizer, negar, omitir, silenciar, organizar, selecionar o que vai dizer. Memória, para Halbwachs (1990) faz parte de um processo social em que os indivíduos não são vistos como seres isolados, eles interagem ao longo de suas vidas a partir de estruturas sociais determinadas.

\section{PRÁTICA DE INCLUSÃO E EXPERIÊNCIAS DE PROFESSORES E ALUNOS NO ENSINO MÉDIO}

Compreendemos a inclusão, concordando com Mantoan (2006, p. 19), aquela que implica “(...) não deixar ninguém no exterior do ensino regular, desde o começo da vida escolar".

A autora reforça a necessidade das ações educativas terem o destino de todos indistintamente e permitir que estejam aprendendo em conjunto desde a Educação infantil de acordo com a limitação de cada um, já que somos todos diferentes.

A centralidade deste artigo foi para na direção de encontros, de diálogos e das trocas de vivências estabelecidas no cotidiano do Ensino Médio. Foram realizadas com alunos surdos e pesquisadores que relataram momentos de estudo, as dificuldades e superações ocorridas durante esse nível de ensino.

O encontro teve como lócus uma sala de aula do Curso de Pedagogia de uma universidade de Mossoró. Pela manhã, logo nas primeiras horas, nos reunimos com o intuito de travar nossos diálogos com as trajetórias escolares vividas por alunos e professores de alunos surdos que cursam 70 período. Com uma intérprete iniciamos nossa viagem pelo mundo da inclusão/exclusão no Ensino Médio experenciados pelos referidos alunos. O objetivo seria saber sobre algumas práticas de inclusão neste nível de ensino que permearam seu processo escolar. 
Após explicar o propósito da entrevista, os alunos iniciaram a conversa trazendo suas experiências escolares. Um dos primeiros questionamentos colocados foi sobre o ingresso no Ensino Médio. Estudaram em uma instituição de Educação de Jovens e Adultos da cidade de Mossoró/RN tendo como motivo, principal da escolha, o fato de poderem terminar os estudos em dois anos. O menor tempo para o término daria condição para o ingresso, também mais rápido, no mercado de trabalho.

O ingresso no supletivo se deu através apenas do preenchimento da ficha de matrícula, realizado com o auxílio de uma intérprete de Libras já que a instituição não disponibilizava o trabalho com esse profissional.

Apontam ter sido um processo marcado por algumas dificuldades desde a não disponibilização de intérprete na sala de aula até os momentos de atividades, trabalhos e provas. Sentiam que ficava em sua responsabilidade e na família a busca por um atendimento especializado para suprir as dificuldades de compreensão dos conteúdos e atender às atividades escolares propostas pela modalidade de Educação de Jovens e Adultos.

A relação família-escola não se constituía em uma prática sistemática, pois a escola não tinha uma visão de participação permanente. As idas pontuais da família à escola aconteciam por iniciativa da própria família.

Outra dificuldade sentida por eles se aloja na prática do ensino e da aprendizagem em sala de aula. A metodologia cotidiana concentrava-se apenas na cópia do que era escrito na lousa pela professora. Essa postura pedagógica implicava na dificuldade de entendimento. Os alunos entendiam pouco do que a professora falava. Ainda era pouco comum as professoras se preocupavam se os alunos haviam entendido ou não o conteúdo.

As metodologias utilizadas pelos professores tinham como recurso a lousa, o lápis de quadro e às vezes filme com legenda. Dizem sobre a ausência de metodologias variadas para incluir e que, por essa razão, sentiam-se desestimulados e desinteressados.

Como instrumentos de avaliação tinham as provas e trabalhos que não eram realizadas na própria instituição, mas no atendimento especializado. Nesse processo, alguns professores mantinham contato com os professores do atendimento especializado, preocupados com a aprendizagem dos alunos surdos. Eram poucos. Outros, no entanto, apenas entregavam a atividade que era levada pelos próprios alunos ao Centro de Atendimento Especializado.

A relação com os demais alunos apresentava limites, pois as dificuldades de compreensão da Língua de Sinais e vice versa, criava barreiras e afastamentos. As barreiras da comunicação foi uma dimensão bastante forte e impeditiva de amadurecimento de todo. Ouvintes não entendiam o que os surdos falavam, surdos não entendiam o que os ouvintes falavam. Um aluno afirma ainda que nos trabalhos em grupo a comunicação continuava sendo um grande entrave para o entendimento de ambas as culturas (surda e ouvinte). Um deles destaca que "havia colegas que faziam zombarias chamando-os para brigar e se envolver com coisas erradas". A resistência aos convites era cotidiana.

Sobre qual disciplina eles mais gostavam, um deles respondeu que era Língua Portuguesa, História e Geografia. Além de serem as disciplinas com as quais mais se envolviam, consideram interessantes e ainda por que os professores davam maior atenção trazendo recursos visuais e dialogavam com os alunos propondo atividades teatrais, utilização do corpo com atividades lúdicas.

Outro ponto de vista sobre esse mote é com respeito à preferência entre as disciplinas. Destacam como negativo a Matemática. Sentiam que a exigência rigorosa do professor e sua prática os discriminavam. 
Sobre preconceito salientam que alguns colegas não queriam fazer trabalho com eles e que alguns professores não se importavam com seu aprendizado. Estes explicavam suas aulas e não queriam saber se estavam aprendendo. Consideram que não eram incluídos no espaço de sala de aula.

Vale lembrar que não só a falta de estrutura das escolas é um problema, mas a frequência desses alunos na escola regular, em seus primeiros anos da mesma forma. O processo de aceitação da turma, e a relação deles com o professor, é um dos robusto impedimentos dos pais quanto à entrada dos seus filhos em uma escola comum.

Mazzotta, (1989, pp. 43-4) fala que "a interação, mediante a comunicação, a assimilação, pela participação ativa e reconhecida do excepcional como elemento do grupo de crianças "normais" e, finalmente, a aceitação, refletida na aprovação da criança excepcional como elemento participante e aceito no grupo, mediante relações regulares e espontâneas que fazem com que o excepcional se sinta parte natural do grupo". Percebemos a importância da eliminação das barreiras da comunicação como necessidade urgente.

Ao tratarmos dessa purgação pensamos que há um direito assegurado, também, na lei de Diretrizes e Bases da Educação Nacional. Temos na LDB que o ensino especial é uma modalidade e como tal, deve perpassar o ensino comum em todos os seus níveis (da escola básica, ensino médio a nível superior). Há que assegurar não apenas o acesso, mas a permanência e o prosseguimento do estudo desses alunos e não retirar do estado, por nenhum motivo, essa obrigação, exigindo, postulando o cumprimento das leis, para atender às necessidades educacionais de todos.

Desconhecer os seus direitos fez pais ficarem calados quanto à submissão ao sistema escolar, que simplesmente não aceitavam seus filhos com suas limitações. Situações como essa dificultaram por muito tempo a disseminação da inclusão. Hoje, a causa inclusiva tem o referencial da lei que permitem acesso a uma educação eficaz a todos independente de gênero, deficiência, língua ou classe social.

A respeito do estudo em casa afirmaram que liam os textos, os conteúdos da escola embora com muita dificuldade de interpretação fato que os levava a tirar as dúvidas no atendimento especializado. Ao trabalharem sozinhos nada entendiam.

Sobre essa dificuldade um deles assinala sobre a necessidade de uma relação intensa entre os professores da escola e o Centro de Apoio Especializado. Consideram fundamental a apropriação sobre a Língua Brasileira de Sinais, sua estrutura, sua escrita, sua leitura. Sentem-se prejudicados na hora da correção, considerando que os professores corrigem a partir da estrutura da Língua Portuguesa. Ainda acrescentam a estranheza quando se deparam com textos escritos em LIBRAS.

Quando questionado sobre a aprendizagem dos conteúdos do Ensino Médio durante seu período de estudo na EJA, confessaram que não aprenderam muita coisa. $O$ esquecimento de quase todos os conteúdos levam como causa a barreira da comunicação. Matemática, Inglês e Português são as disciplinas destacadas como maior nível de dificuldades por duas razões, eles repisam, a saber, o não entendimento da LIBRAS, Metodologias e falta de intérprete por parte dos professores.

Reportam-se ao "direito de igualdade das pessoas com deficiência, que são pessoas diferentes, mas que todos têm sua capacidade". Ainda que é preciso "dar oportunidade para a pessoa com deficiência mostrar a sua capacidade". 
Compreendemos que ambos os alunos consideram importante a inclusão ser exercitada em todas as dimensões da vida de um aluno, oportunizando encontros, palestras, projetos, bem como a adesão de todos aqueles que fazem os processos educativos.

Entendemos que, com o relato de vida construído pelos alunos surdos a partir das experiências no Ensino Médio, fica claro, que a integração permeou todo esse grau de escolaridade. Aproximam-se do que advoga Mantoan (2006, p. 18), integração corresponde "a uma concepção de inserção parcial, porque o sistema prevê serviços educacionais especializados".

Para esta autora, essa posição da escola, de educadores e outros segmentos, em seu olhar sobre a deficiência, implicam em integração. Esse entendimento reforça a idéia de que a pessoa com deficiência deve se adaptar às condições da realidade da escola. Essa postura não é inclusão e sim adaptação. Sozinhos, o surdo não consegue desenvolver a aprendizagem e, então, a necessidade de procurar o turno contrário para o serviço especializado.

O que acontece, em decorrência dessa situação, é a escola e os professores de ensino regular ficarem dependentes, se acomodam com o auxílio do atendimento especializado. A transferência de tarefas, para outro profissional, o que é de sua competência, também, considerado de extrema importância deixa, de certa forma, os profissionais da educação sem busca de formação continuada.

Mantoan (2006, p. 19) afirma que "na perspectiva inclusiva, suprime-se a subdivisão dos sistemas escolares em modalidades de ensino especial e regular. As escolas atendem às diferenças sem discriminar ou trabalhar à parte com alguns alunos (...)".

\section{CONSIDERAÇÕES FINAIS}

A importância de repensar o que precisa mudar na Educação Brasileira fica evidente através das vozes dos alunos. Para auxiliar a formação de alunos com deficiência no Ensino Médio na escola comum será necessário uma mudança de olhar, de sentir, de fazer educação. Implica na busca sistemática da formação continuada.

Na construção dessas (auto) biografia, as experiências dos sujeitos escolares, alunos e professores, nos fazem refletir se realmente a educação atinge a todos e se é feita com qualidade. Ficou claro que a ausência de um intérprete de LIBRAS, somado à questão das metodologias são pontos vitais no processo de inclusão que quer uma educação de qualidade.

Não só entrar em uma sala de aula através de uma matrícula "fria" seja suficiente para preparar este, socialmente e pedagogicamente.

Através dos relatos dos alunos percebemos que há falhas no processo de inclusão e permanência o que vai apontar lacunas no Sistema Educacional Brasileiro. Professores com pouca familiaridade teórica e prática para lidar com as limitações dos alunos e promover um ensino de qualidade para todos, despreocupação com a presença dos alunos com deficiência em sala de aula, recursos metodológicos sem o acompanhamento do que o cenário contemporâneo apresente.

Salientamos que este estudo, esta aproximação ao aluno surdo quanto ao seu percurso no Ensino Médio, via (auto) Biografia, demonstra que a escuta de suas narrativas são recursos para a ação, intervenção e mudanças. Foi o que aconteceu com os alunos aqui ouvidos ao afirmar que hoje, na universidade, conseguiram mobilizar sua turma, e a faculdade, para a promoção de curso de LIBRAS. 


\section{REFERÊNCIAS}

1. BUENO, Belmira O; CATANI, Denice B.; SOUSA, Cynthia Pereira (Org.). A vida e o ofício dos professores: formação contínua, autobiografia e pesquisa em colaboração. São Paulo: Escrituras Editora, 1998.

2. BRASIL. Leis de Diretrizes e Bases da Educação no Brasil: http://www.planalto.gov.br/ccivil_03/leis/L9394.htm.

3. BRASIL. Decreto no 5.626, de 22 de dezembro de 2005. http://www.planalto.gov.br/ccivil_03/_ato2004-2006/2005/decreto/d5626.htm

4. BRASIL. Resolução CNE/CEB (no 02 Art. 4o Inciso I de 2001). http://www.pedagogiaemfoco.pro.br/Iress2_01.htm

5. FERRAROTTI, Franco. Sobre a autonomia do método Biográfico. Texto publicado em Sociologie de la connaisance. DUVIGNAUD, Jean (Coord.) Paris; Payot, 1979.

6. MANTOAN, Maria Teresa Égler. Inclusão escolar: o que é? Por quê? Como fazer? 2 ed., São Paulo: Moderna, 2006.

7. MANTOAN, Maria Teresa Égler; PRIETO, Rosângela Gavioli Prieto; ARANTES, Valéira Amorim (Orgs.). Inclusão escolar: pontos e contrapontos. São Paulo : Summus editorial, 2006.

8. MAZZOTTA, Marcos José da Silveira. Evolução da Educação Especial e as Tendências da Formação de Professores de Excepcionais no Estado de São Paulo. Tese de doutorado Faculdade de Educação da Universidade de São Paulo: SP, 1989.

9. NÓVOA, Antonio. (Org.). Os professores e sua formação. Lisboa: Publicações Dom Quixote, 1997.

10. PASSEGI, Maria da Conceição (Org.). Tendências da Pesquisa (auto) Biográfica. Natal: EDUFRN; São Paulo: Paulus, 2008.

11. PASSEGI, Maria da Conceição; SOUZA, Eliseu Clementino; VECENTINI, Paula Perin. Entre a vida e a formação: pesquisa (auto) Biográfica, Docência e Profissionalização. Educação em Revista: Belo Horizonte, 2011.

12. SOUZA, Eliseu Clementino de. História de Vida e formação de professores: um olhar sobre a singularidade das narrativas (auto) biográficas. In: MACEDO, Roberto Sidney (Org.)- Currículo e Docência: tensões contemporâneas interfaces pós-formais. Salvador: Editora da UNB, 2003. 